\title{
Perfil profissional e sociodemográfico dos terapeutas ocupacionais do Estado do Paraná, Brasil
}

\section{Occupational therapists professional and sociodemographic profile in Paraná, Brazil}

\author{
Milton Carlos Mariotti ${ }^{1}$, Rafaella Stradiotto Bernardelli ${ }^{2}$, Renato Nickel $^{3}$, Abdo \\ Augusto Zeghbi ${ }^{4}$, Maria Luiza Vautier Teixeira ${ }^{5}$, Ruy Moreira da Costa Filho ${ }^{6}$
}

http://dx.doi.org/10.11606/issn.2238-6149.v27i3p313-321

Mariotti MC, Bernardelli RS, Nickel R, Zeghbi AA, Teixeira MLV, Costa Filho RM. Perfil profissional e sociodemográfico dos terapeutas ocupacionais do Estado do Paraná, Brasil. Rev Ter Ocup Univ São Paulo. 2016 set.-dez;27(3):313-21.

RESUMO: O conhecimento do perfil dos terapeutas ocupacionais, tendências na formação e mercado de trabalho permitem o vislumbre da identidade da profissão e a projeção de tendências futuras. Objetivo: Traçar o perfil profissional e sociodemográfico de terapeutas ocupacionais do Paraná em 2015. Método: Pesquisa quantitativa, observacional, de caráter transversal, realizada por meio de questionário respondido por amostra representativa de 188 dos 680 profissionais inscritos no Conselho Profissional. Resultados: O conjunto de profissionais do Paraná inscritos é constituído predominantemente por mulheres jovens e se concentra na capital do estado. A maioria graduou-se nos últimos 10 anos, possui pósgraduação latu sensu, porém poucos possuem mestrado ou doutorado. A maioria trabalha exclusivamente na profissão, num único emprego, em instituição pública, com carga horária de 6 horas diárias. As principais áreas de atuação são Saúde Mental, Saúde Funcional, Contextos Sociais e Contextos Hospitalares . A renda mensal varia entre o piso e 4 mil reais. Conclusão: Nos últimos 15 anos houve aumento expressivo no número de profissionais e na qualificação deles. O perfil profissional demonstrou que a profissão está em fase de amadurecimento e consolidação no mercado de trabalho.

DESCRITORES: Terapia ocupacional; Ocupações em saúde; Inquéritos demográficos.
Mariotti MC, Bernardelli RS, Nickel R, Zeghbi AA, Teixeira MLV, Costa Filho RM. Occupational Therapists Professional and Sociodemographic Profile in Paraná, Brazil. Rev Ter Ocup Univ São Paulo. 2016 Sept.-Dec;27(3):313-21.

\begin{abstract}
The knowledge on the occupational therapists profile, trends in education and the labor market, allows us to have a glimpse of the profession identity and project future trends. Objective: To describe the professional and socio-demographic profile of Paraná occupational therapists in 2015. Method: This is a quantitative, observational and cross-sectional research, performed by means of a questionnaire answered by a representative sample of 188 of the 680 registered professionals in the Professional Council. Results: The Paraná professionals constitute predominantly young women and live on the state capital. Most graduated in the past 10 years, latu sensu, but few have master's or doctorate degree. Most works exclusively in the profession, a single job, in a public institution, with a schedule of 6 hours daily. The main areas of focus are Mental Health, Functional Health, Social Contexts and Hospital Contexts respectively. The monthly income varies between the wage floor and 4 thousand Brazilian Reais. Conclusion: In the last fifteen years, there has been significant increase in the number of professionals and qualification of these. The professional profile demonstrated that the profession is maturing and consolidation in the labor market.
\end{abstract}

KEYWORDS: Occupational therapy; Health occupations; Population surveys.

1. Universidade Federal do Paraná - UFPR, Departamento de Terapia Ocupacional, Laboratório de Pesquisas de Terapia Ocupacional em Saúde Mental. Conselheiro Efetivo e Membro da Comissão Científica do Crefito-8. Email: miltoncarlosmariotti@gmail.com.

2. Pontifícia Universidade Católica do Paraná - PUCPR, Doutoranda do Programa de Pós Graduação em Tecnologia em Saúde. Membro da Comissão Científica do Crefito-8. Email: rafaella.bernardelli@gmail.com.

3. Universidade Federal do Paraná - UFPR, Departamento de Terapia Ocupacional, Laboratório de Pesquisas em Reabilitação e Saúde do Trabalhador. Conselheiro Efetivo e Diretor Tesoureiro do Crefito-8. Email: renatonickel@hotmail.com.

4. Conselheiro Efetivo e Presidente do Crefito-8. Email: zeghbiabdo@hotmail.com.

5. Terapeuta Ocupacional do Hospital de Clinicas da Universidade Federal do Paraná - HC/UFPR. Conselheira Efetiva e Diretora Secretária do Crefito-8. Email: mariavautier@gmail.com

6. Universidade Estadual de Londrina - UEL, Departamento de Fisioterapia. Conselheiro Efetivo e Vice-Presidente do Crefito-8. Email: ruy.costa1@yotmail.com.

Endereço para correspondência: Departamento de Terapia Ocupacional da UFPR. Campus Jardim Botânico. Av. Lothário Meissner, 632 - Jardim Botânico, Curitiba, PR. CEP: 80.210-170. 


\section{INTRODUÇÃO}

Terapia Ocupacional é um campo de
conhecimento e de intervenção em saúde,
educação e na esfera social que reúne tecnologias orientadas para a emancipação e autonomia de pessoas que, por razões ligadas a problemáticas específicas, físicas, sensoriais, mentais, psicológicas e/ou sociais, apresentam temporária ou definitivamente dificuldades na inserção e participação na vida social ${ }^{1}$.

O decreto-lei 938, de 13 de outubro de 1969, regulamenta a profissão e define as atividades profissionais, direitos e deveres do terapeuta ocupacional, garantindo a autonomia profissional ${ }^{2}$.

O crescimento da profissão no país pode ser evidenciado quando se observa que em 2001 existiam 29 cursos de graduação que,em 2014, eram 73, com mais um Programa de Pós-Graduação Strictu Sensu na Universidade Federal de São Carlos - UFSCar ${ }^{3}$.

Atualmente, no Brasil, há 17.500 profissionais registrados no sistema - Conselho Federal de Fisioterapia e Terapia Ocupacional/Conselhos Regionais de Fisioterapia e Terapia Ocupacional (COFITTO/ CREFITOs) ${ }^{4}$. A população brasileira está estimada em mais de 204 milhões de habitantes, o que dá uma média de 0,9 terapeuta ocupacional para cada 10 mil habitantes ${ }^{5}$. A World Federation of Occupational Therapy (WFOT), em estudo sobre recursos humanos no ano de 2014, divulgou que a média mundial é de 2 profissionais para cada 10 mil habitantes ${ }^{6}$. Esses dados apontam para a existência de espaço de trabalho para terapeutas ocupacionais no mercado brasileiro.

No Estado do Paraná, esta proporção é ainda menor, de 680 profissionais para uma população de mais de 11 milhões de habitantes, média de 0,06 terapeuta ocupacional por mil habitantes ${ }^{7}$.

$\mathrm{O}$ amadurecimento e a consolidação de uma profissão dependem do trabalho de seus profissionais, no qual se amplia e aprimora o conhecimento, gerando diretrizes para uma atuação profissional eficiente e eficaz ${ }^{8}$. Isto é, a prática clínica é gerada a partir da integração de experiências individuais vivenciadas na atuação profissional, associada ao conhecimento de evidências científicas de qualidade disponíveis na literatura e ao arcabouço da legislação que regulamenta o exercício profissional ${ }^{2,8}$.

Uma profissão de saúde consolidada consegue preparar os seus membros para atender as necessidades da população, assim como prever demandas futuras. Essa consolidação está vinculada a: conhecimento da mão de obra disponível, tendências em sua formação, produção científica e mercado de trabalho, identificando deficiências e expertises, para assim projetar e planejar tendências futuras ${ }^{8}$.

As entidades de classe, especialmente os conselhos profissionais, por possuírem o papel de fiscalização do exercício profissional, têm o dever de apontar as deficiências e o potencial dos profissionais que compõem sua categoria ${ }^{9}$. A universidade, por sua vez, tem o dever de adequar os processos de formação às exigências da atuação profissional ${ }^{10}$. A realização de pesquisas para o conhecimento do perfil profissional e sociodemográfico é um caminho para o conhecimento da realidade e o planejamento de ações das entidades de classe e das instituições de ensino em prol do desenvolvimento da profissão.

Diante dessa demanda e dos poucos estudos que abordam o perfil do terapeuta ocupacional no estado do Paraná, o Conselho Regional de Fisioterapia e Terapia Ocupacional da Oitava Região (CREFITO 8) em parceria com a Universidade Federal do Paraná (UFPR) decidiram pela realização desta pesquisa.

\section{OBJETIVO}

Traçar o perfil profissional e sociodemográfico de terapeutas ocupacionais do Estado do Paraná no ano de 2015.

\section{PROCEDIMENTOS METODOLÓGICOS}

Esta é uma pesquisa quantitativa, transversal, de caráter observacional e descritivo, realizada em parceria entre pesquisadores da UFPR e o CREFITO-8.

A população estudada foram os 680 profissionais terapeutas ocupacionais registrados no CREFITO-8, jurisdição do Estado do Paraná. Foi realizado um cálculo amostral, com $90 \%$ de confiança, totalizando uma amostra final de 188 profissionais participantes. Todos os profissionais terapeutas ocupacionais registrados no CREFITO-8 foram convidados a participar de forma voluntária, por meio de e-mail, redes sociais e site institucional.

Este estudo seguiu a resolução 466/12 e teve parecer favorável do Comitê de Ética em Pesquisa em Seres Humanos do setor de Ciências da Saúde da Universidade Federal do Paraná (CEP-UFPR), número 1.062.506, de 13/5/2015. As informações foram coletadas por meio de questionário semiestruturado, criado especificamente para esse fim e baseado em questionários utilizados em pesquisas similares ${ }^{8,11,12,13}$.

O questionário, construído por meio do aplicativo Google Forms, foi composto por 35 questões, sendo 33 fechadas e 2 abertas. Para este estudo foram utilizados os primeiros 188 questionários respondidos entre os meses de maio e agosto de 2015 . 
Após a obtenção das respostas, os dados foram organizados em tabelas no programa Excel 2010 eas questões, agrupadas em três grandes tópicos: Perfil Sociodemográfico; Perfil de Formação e Perfil Profissional. Nesta publicação foram levadas em conta apenas as questões fechadas do questionário. Vale ressaltar que nas questões relativas à área de especialização e área de atuação profissional foi utilizada como critério a terminologia proposta pelo COFFITO para as áreas de especialidade profissional, tendo sido acrescidos os itens docência e outros.

As variáveis numéricas foram categorizadas em: idade, com faixas etárias de 10 anos; ano de formação (graduação, especialização, mestrado e doutorado), em períodos de conclusão de 5 anos, e cidades em macrorregiões.

Os dados foram analisados no pacote estatístico SPSS versão 22.0. Todos os resultados do perfil profissional e sociodemográfico foram descritos por meio de frequência absoluta e percentual. A variável faixa de renda foi associada e correlacionada às variáveis: faixa etária, período de conclusão da graduação e vínculo profissional por meio de teste Qui-quadrado e Correlação de Pearson, com significância estatística estipulada em 95\%.

\section{RESULTADOS}

\section{Perfil sóciodemográfico}

As características sociodemográficas do grupo investigado evidenciaram que $91 \%$ dos profissionais são mulheres, $82,4 \%$ têm idade entre 21 e 40 anos, a maioria, $54,8 \%$, vive em união conjugal e $62,2 \%$ não têm filhos ou dependentes.
O CREFITO-8, para efeitos de fiscalização, divide o Estado do Paraná em quatro macrorregiões: Curitiba, Cascavel, Londrina e Maringá. Cada macrorregião é composta pela cidade que a denomina e por um grupo de cidades em seu entorno. Na pesquisa observa-se que a maioria dos profissionais reside na macrorregião de Curitiba (61,2\%), seguida pelas macrorregiões de Cascavel $(18,1 \%)$, Londrina $(12,2 \%)$ e Maringá $(8,5 \%)$. Destaca-se que $17,6 \%$ dos profissionais trabalham em cidade diferente da que reside, embora na mesma macrorregião.

\section{Perfil de formação}

Em relação à graduação, $60,7 \%$ dos participantes concluíram o curso entre 2006 e 2014 (Tabela 1). As instituições paranaenses apresentam-se como as principais formadoras dos profissionais respondentes $(61,2 \%)$, seguidas pelas instituições paulistas, que formaram $20,8 \%$. Dos graduados no estado do Paraná, 41,5\% formaram-se em instituição pública federal.

Quanto à pós-graduação latu sensu, 62,2\% (117) relataram ter cursado ou estar cursando especialização; desses, 60,7\% (71) o fizeram a partir de 2011 (Tabela 1) e $9,3 \%$ (11) cursaram em mais de uma área. A distribuição desses profissionais por área de especialização está demonstrada na Tabela 2.

Com relação à pós-graduação stricto sensu, apenas $10,1 \%$ cursaram ou estão cursando mestrado, com maior ocorrência a partir de $2011(42,1 \%)$. O doutorado apresenta um índice ainda menor, $2,1 \%$ de doutores ou doutorandos, que se titularam ou entraram em processo de titulação a partir de 2006 (Tabela 1).

Tabela 1 - Distribuição em frequência absoluta $(\mathrm{N})$ e relativa $(\%)$ dos terapeutas ocupacionais de acordo com a formação e período de conclusão

\begin{tabular}{|c|c|c|c|}
\hline Curso & Período & $\mathbf{N}$ & $\%$ \\
\hline \multirow{7}{*}{ Graduação } & De 2011 a 2014 & 58 & 30,9 \\
\hline & De 2006 a 2010 & 56 & 29,8 \\
\hline & De 2001 a 2005 & 33 & 17,6 \\
\hline & De 1996 a 2000 & 18 & 9,6 \\
\hline & De 1991 a 1995 & 10 & 5,3 \\
\hline & 1990 antes & 13 & 6,9 \\
\hline & Total & 188 & 100 \\
\hline \multirow{6}{*}{ Pós graduação Especialização } & De $2011 \mathrm{a}$ em andamento & 71 & 60,7 \\
\hline & De 2006 a 2010 & 19 & 16,2 \\
\hline & De 2001 a 2005 & 18 & 15,4 \\
\hline & De 1996 a 2000 & 2 & 1,7 \\
\hline & 1995 antes & 7 & 6,0 \\
\hline & Total & 117 & 100 \\
\hline \multirow{5}{*}{ Pós graduação Mestrado } & De $2011 \mathrm{a}$ em andamento & 8 & 42,1 \\
\hline & De 2006 a 2010 & 5 & 26,3 \\
\hline & De 2001 a 2005 & 5 & 26,3 \\
\hline & De 1996 a 2000 & 1 & 5,3 \\
\hline & Total & 19 & 100 \\
\hline \multirow{3}{*}{ Pós graduação Doutorado } & De $2011 \mathrm{a}$ em andamento & 1 & 25 \\
\hline & De 2006 a 2010 & 3 & 75 \\
\hline & Total & 4 & 100 \\
\hline
\end{tabular}


Mariotti MC, et al. Perfil profissional e sociodemográfico dos terapeutas ocupacionais. Rev Ter Ocup Univ São Paulo. 2016 set./dez.;27(3):313-21.

Tabela 2 - Distribuição em frequência absoluta (N) e relativa (\%) dos terapeutas ocupacionais por área de especialização cursada e título de especialista profissional

\begin{tabular}{|c|c|c|c|c|}
\hline & \multicolumn{2}{|c|}{ Área de especialização } & \multicolumn{2}{|c|}{ Título de especialista profissional } \\
\hline & $\mathrm{N}$ & $\%$ & $\mathrm{~N}$ & $\%$ \\
\hline Saúde Mental & 45 & 34,4 & 5 & 41,6 \\
\hline Saúde Funcional & 30 & 22,9 & 0 & 0 \\
\hline Contextos Hospitalares & 10 & 7,6 & 1 & 8,3 \\
\hline Saúde Coletiva & 8 & 6,1 & 0 & 0 \\
\hline Acupuntura & 7 & 5,3 & 2 & 16,6 \\
\hline Contextos Sociais & 6 & 4,6 & 4 & 33,3 \\
\hline Saúde da Família & 2 & 1,5 & 0 & 0 \\
\hline Docência & 8 & 6,1 & - & - \\
\hline Outras & 15 & 11,5 & - & - \\
\hline Total & 131 & 100 & 12 & 100 \\
\hline
\end{tabular}

\section{Perfil profissional}

Apenas 2,7\% dos profissionais que responderam ao questionário não estão atuando na profissão, $85,1 \%$ trabalham exclusivamente com a profissão e 12,2\% atuam também fora dela.

Em relação ao número de empregos, $55,3 \%$ dos profissionais relataram possuir um único emprego, $25 \%$, dois empregos, $12,8 \%$, três, $3,2 \%$, mais que três e $3,7 \%$ afirmaram estar desempregados.

Sobre o tipo de instituição em que trabalham (pública, privada ou filantrópica), 52,5\% dos profissionais responderam que trabalham apenas em instituições públicas, seguidos por 16,6\% que trabalham apenas em instituições particulares e 18,2\% que trabalham em instituições filantrópicas. Os $12,8 \%$ restantes relataram trabalhar em mais de um desses três tipos de instituição.

Dos que têm emprego público, 50,9\% trabalham em instituições municipais, 30,4\%, em estaduais, 14,3\%, em federais e $4,5 \%$ dizem ter mais que um emprego público.

Com relação ao vínculo trabalhista, a maioria, $38,9 \%$ é celetista, seguida dos estatutários, que representam $30,8 \%$, autônomos, que somam $23,1 \%$, empresários do ramo, $3,2 \%$, residentes e bolsistas totalizam $2,7 \%$ e, por fim, os cooperados, que são 1,4\%.

Quanto à carga horária de trabalho, 37,2\% dos terapeutas ocupacionais trabalham 6 horas, 33\%, 8 horas, $20,7 \%$, mais que 8 e apenas $6,4 \%$, menos que 6 horas diárias.

Em relação ao nível de atenção à saúde, 35,8\% relataram trabalhar em mais de um nível de atenção à saúde, sendo que $43,6 \%$ trabalham na atenção terciária, $36,7 \%$, na atenção secundária e apenas $15,5 \%$, na primária, além dos $4,4 \%$ que atuam na docência.
$\mathrm{Na}$ distribuição dos profissionais de acordo com a área de atuação, $123(65,4 \%)$ trabalham em uma única área e $65(34,6 \%)$ trabalham em mais que uma área de atuação. Deve-se considerar que um mesmo respondente pode trabalhar em mais de uma área, totalizando um número de respostas maior que o número de respondentes da pesquisa (Tabela 3).

Tabela 3 - Distribuição em frequência absoluta $(\mathrm{N})$ e relativa (\%) de acordo com a área de atuação profissional

\begin{tabular}{l|c|c}
\hline Área de atuação & N & \% \\
\hline Saúde Mental & 90 & 30,4 \\
\hline Saúde Funcional & 79 & 26,7 \\
\hline Contextos Sociais & 53 & 17,9 \\
\hline Contextos Hospitalares & 27 & 9,1 \\
\hline Saúde da Família & 17 & 5,7 \\
\hline Saúde Coletiva & 16 & 5,4 \\
\hline Docência & 12 & 4,1 \\
\hline Acupuntura & 2 & 0,7 \\
\hline Total & 296 & 100 \\
\hline
\end{tabular}

Observa-se que a área de Saúde Mental é a que apresenta o maior número de profissionais atuantes (30,4\%), seguida das áreas de Saúde Funcional (26,7\%), Contextos Sociais (17,9\%) e Contextos Hospitalares, com 9,1\%. Sendo assim, mais de $84 \%$ dos terapeutas ocupacionais paranaenses atuam nessas quatro áreas.

Em relação à renda mensal, 55,6\% (100) dos terapeutas ocupacionais recebem salários entre o piso salarial profissional (R\$1.831,70) e 4 mil reais, seguidos de $22,8 \%$ (41) com renda mensal igual ou menor que o piso salarial, $18,9 \%$ (34) que recebem entre 4 e 8 mil reais e 2,8\% (5) que recebem acima de 8 mil reais (Figura 1 ). 


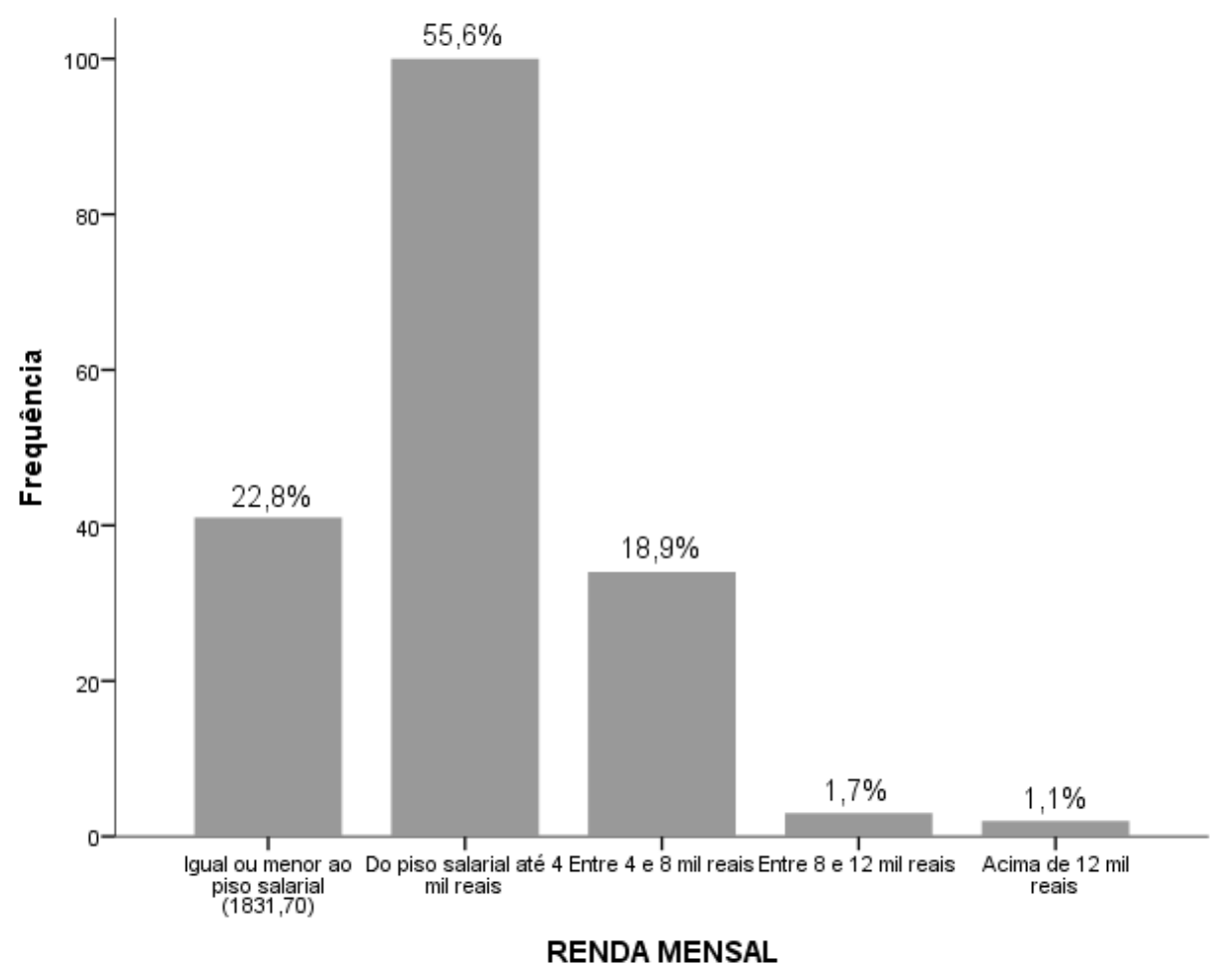

Figura 1 - Renda mensal: distribuição numérica e percentual

Ao avaliar a associação entre faixa de renda e faixa etária, observa-se que são dependentes entre si $\left(\mathrm{X}^{2}=\right.$ $47,812$ e p $<0,001)$ e têm correlação positiva $(\mathrm{R}=0,475$ e $\mathrm{P}<0,001)$. O mesmo é observado ao se testar a associação entre faixa de renda e tempo de formação $\left(\mathrm{X}^{2}=89,821 \mathrm{p}\right.$ $<0,001, \mathrm{R}=0,558$ e $\mathrm{P}<0,001)$. Na faixa de renda igual ou menor que o piso salarial predominam os profissionais que têm de 21 a 30 anos $(75,6 \%)$ e formados de 2011 a $2015(56,1 \%)$. Na faixa de renda que vai do piso até 4 mil reais há maior concentração de profissionais de 21 a 30 anos (54\%) e graduados entre 2006 e 2010 (32\%). Dos que recebem entre 4 e 8 mil reais, 50\% têm idade entre 31 a 40 anos e concluíram a graduação entre 2001 e 2005 (26,5\%). Aqueles que estão na faixa de renda entre 8 e 12 mil reais têm maioria concentrada na faixa de 41 a 62 anos $(66,6 \%)$ e graduaram-se antes de 1990 (66,7\%). Por fim, 100\% dos que recebem acima de 12 mil reais encontram-se na faixa etária entre 41 e 62 anos e graduaram-se antes de 1990.

Ao analisar a relação entre vínculo de trabalho e faixa de renda dos que possuem apenas um emprego, verifica-se que o tipo de vínculo influencia o salário $\left(\mathrm{X}^{2}\right.$ $=62,779, \mathrm{p}<0,001)$. A maioria dos que possuem vinculo de estatutário ou celetista têm renda mensal entre o piso salarial da categoria e 4 mil reais $(43,4 \%$ e $66,7 \%$ respectivamente), porém, o segundo maior grupo entre os estatutários $(41,5 \%)$ recebe entre 4 e 8 mil reais, enquanto que o segundo maior grupo entre os celetistas $(31,7 \%)$ tem renda igual ou menor que o piso salarial. Apenas os estatutários atingem as faixas de renda a partir de $8 \mathrm{mil}$ reais. Já o maior grupo entre os profissionais autônomos concentra-se na faixa de renda mais baixa $(50 \%)$ seguidos pelos que têm renda entre o piso e 4 mil reais $(31,9 \%)$.

Observa-se ainda relação de dependência entre a área de atuação daqueles que atuam exclusivamente em uma área e renda mensal $\left(\mathrm{X}^{2}=56,343, \mathrm{p}<0,001\right)$. Embora a faixa de renda predominante em todas as áreas de atuação seja do piso salarial da categoria até 4 mil reais, os que trabalham nas áreas de Saúde Funcional, Saúde Mental, Contextos Hospitalares, Contextos Sociais e Docência são os que atingem as faixas de renda acima de 4 mil reais.

Os participantes foram por fim questionados sobre as principais dificuldades encontradas na atuação profissional. A remuneração foi apontada como principal dificuldade por $27,9 \%$ dos participantes, seguida por falta 
de identidade e reconhecimento profissional $(23,7 \%)$, falta de valorização $(22,2 \%)$, de acesso a conhecimentos técnicos científicos $(10,1 \%)$, de autonomia $(7,5 \%)$, de inserção $(7,0 \%)$ e ainda outras dificuldades $(1,5 \%)$.

\section{DISCUSSÃO}

Para a discussão dos dados, em função da escassez de estudos do perfil de terapeutas ocupacionais no Paraná, recorreu-se a estudos de perfil de terapeutas ocupacionais de outros estados e de outras profissões da área da saúde.

A predominância de mulheres foi observada também em outros estudos, como o da Federação Mundial de Terapeutas Ocupacionais, em seu levantamento publicado em 2014, que mostra que $83 \%$ desses profissionais no mundo são do sexo feminino e que no Brasil essa porcentagem é de $99 \%$. Um estudo no Rio Grande do Sul mostrou que 93,6\% dos terapeutas ocupacionais do estado são mulheres ${ }^{14}$. Outras profissões da área de saúde também apresentam alta porcentagem de mulheres, o que é evidenciado em um estudo desenvolvido com fisioterapeutas na cidade de Londrina, no Estado do Paraná ${ }^{15}$ e outro desenvolvido com nutricionistas em nível nacional ${ }^{11}$.

Esse elevado número de mulheres nessas profissões parece estar relacionado aos antecedentes morais do cuidado à saúde, ligados às características femininas. As profissões da área da saúde são as que contemplam atualmente o maior número de mulheres ${ }^{16,17}$.

$O$ fato identificado de que a maioria dessas profissionais são jovens (entre 21 e 40 anos) corrobora estudo de formação e perfil do terapeuta ocupacional no Rio Grande do Sul ${ }^{14}$. Acredita-se que isso esteja relacionado ao perfil de formação, ou seja, o presente estudo mostrou que $67 \%$ graduaram-se nos últimos 10 anos, o que se justifica pelo crescimento do número de cursos de graduação em Terapia Ocupacional ofertados.

No Paraná até o ano 2000 havia apenas um curso de graduação em instituição particular, que ofertava 40 vagas anuais. Em 2001 foi aberto outro curso de graduação, público, na Universidade Federal do Paraná - UFPR, que formou a primeira turma em 2005. A pesquisa mostra que essas duas instituições paranaenses juntas, formaram $61,2 \%$ dos profissionais respondentes da pesquisa e que a UFPR é a instituição que mais formou profissionais que atuam no estado (41,5\%). O fato de uma instituição pública ser a maior formadora de profissionais atuantes no estado corrobora dados encontrados por Akutsu em $2008^{11}$, em sua pesquisa com nutricionistas no Brasil, que mostra que $51,4 \%$ são formados em universidades púbicas.
O fato de a maioria dos profissionais serem formados nos últimos 10 anos também acontece com terapeutas ocupacionais no Rio Grande do Sul, fisioterapeutas no Paraná e nutricionistas no Brasil ${ }^{11,14,15}$. Certamente, esse fato está relacionado com a expansão do número de vagas nos cursos de graduação em Terapia Ocupacional em escolas públicas estaduais e federais no país nos últimos $\operatorname{anos}^{18}$.

A concentração de profissionais paranaenses na macrorregião de Curitiba pode estar relacionada ao fato de que até 2014 o estado só contava com cursos de graduação na capital, indicando a necessidade da interiorização de cursos de graduação. Estudo sobre formação e perfil do terapeuta ocupacional realizado no Rio Grande do Sul observou situação inversa à do Paraná: a maioria dos profissionais $(56,6 \%)$ concentra-se no interior do estado e esse fato é atribuído à descentralização dos cursos de graduação em cidades do interior ${ }^{14}$.

A maioria dos terapeutas ocupacionais do Paraná possui ou está cursando especialização, esse fato também é observado entre os profissionais do Rio Grande do $\mathrm{Sul}^{14}$. O estudo atual demonstrou que a maior parte dos profissionais do Paraná concluiu especialização nos últimos 5 anos, o que pode estar relacionado ao fato de terem concluído a graduação nos últimos 10 anos. Também se relaciona com a abertura das residências multiprofissionais em saúde, que surgiram a partir da lei $\mathrm{n}^{\circ} 11.129$, de 2005 , que foram um incentivo para um maior número de pessoas terem cursado a especialização ${ }^{19}$.

A área de Saúde Mental destaca-se entre as áreas de especialização cursadas e no número de profissionais com título de especialista profissional, conferido pelo COFFITO. A área de Saúde Funcional está em segundo lugar entre as especializações mais cursadas, porém não há nenhum terapeuta ocupacional com título de especialista profissional nessa área, devido ao fato de que até o primeiro semestre de 2016 a prova para essa especialidade ainda não havia sido ofertada, assim como para as áreas de Saúde Coletiva e Saúde da Família.

Com relação à pós-graduação stricto sensu, a pesquisa mostra que $9,6 \%$ dos respondentes possuem mestrado e 2,1\%, doutorado. Embora esses números sejam pequenos, demonstram um crescimento, visto que em 1998 não havia nenhum terapeuta ocupacional com essas titulações no Estado do Paraná ${ }^{20}$. Talvez o maior desafio da profissão atualmente seja a formação de novos pesquisadores que possam avançar e desenvolver os conhecimentos no campo da Terapia Ocupacional ${ }^{18}$.

Destaca-se o fato de que a maioria dos profissionais relatou possuir um único emprego e trabalhar 6 horas 
diárias, o que está de acordo com a lei federal n.8856, de $1^{\circ}$ de março de 1994, a qual limita a jornada de trabalho em 30 horas semanais com o objetivo de preservar a saúde e diminuir o desgaste físico dos profissionais ${ }^{21}$. Esse dado difere da realidade dos profissionais de fisioterapia da cidade de Londrina, PR, que trabalham, em vários locais, além da carga horária fixada ${ }^{15}$. O estudo realizado por Mângia et $\mathrm{al}^{22}$ com terapeutas ocupacionais da área de Saúde Mental aponta que "a obrigatoriedade dos contratos de 30 horas para os terapeutas ocupacionais ao invés de proteger os profissionais os obriga a assumirem dois vínculos, o que os sobrecarrega".

Do total dos profissionais respondentes da pesquisa, a maioria $(52,5 \%)$ respondeu trabalhar apenas em instituições públicas e, desses, 50,9\% trabalham em instituições municipais responsáveis por operacionalizar as atividades do Sistema Único de Saúde - SUS. No entanto, quando perguntados sobre o vínculo trabalhista, $38,9 \%$ responderam ser celetistas e $30,8 \%$, estatutários. Observando esses dados, conclui-se que nem todos os profissionais que trabalham em instituições públicas são estatutários, o que pode estar relacionado à criação das empresas públicas, que surgiram nos últimos anos e contratam em regime celetista.

Nesse cenário é possível inferir que a maioria dos terapeutas ocupacionais do Paraná trabalha no SUS, o que confirma uma tendência nacional descrita por Mângia ${ }^{10}$, que relata a expansão da inserção desses profissionais no SUS.

A pesquisa constatou que a maioria dos profissionais ainda trabalha na atenção terciária, o que decorre do histórico da profissão, que é tradicionalmente reabilitadora. No entanto, um número significativo já trabalha na atenção secundária e apenas um pequeno número na atenção primária, que está se desenvolvendo e sendo estimulada pelas políticas públicas mais recentes ${ }^{23}$.

Esta pesquisa demonstra que a maioria dos terapeutas ocupacionais do Paraná trabalha nas áreas de Saúde Mental (30,4\%), Saúde Funcional (26,7\%), Contextos Sociais $(17,9 \%)$ e Contextos Hospitalares $(9,1 \%)$, que são as mais clássicas na história da profissão.

$\mathrm{O}$ fato de a área de Saúde Mental ser a que tem o maior número de terapeutas ocupacionais trabalhando pode ser justificado pelo maior desenvolvimento de políticas públicas relacionadas à reforma psiquiátrica nos últimos 12 anos, com a criação da Rede de Atenção Psicossocial - RAPS, a qual prevê o terapeuta ocupacional como membro da equipe básica ${ }^{24}$. Provavelmente, esse maior número de empregos na área de Saúde Mental também tenha estimulado um maior número de profissionais a cursar especialização e submeter-se à prova do título de especialista profissional nessa área. A apropriação da história e os referenciais teórico-práticos da reforma psiquiátrica pelo currículo da graduação é um outro aspecto que pode ser considerado importante por ter impulsionado uma prática compromissada com a construção e efetivação da Política Nacional de Saúde Mental².

Já as áreas de Saúde da Família, Saúde Coletiva, Acupuntura e Docência são áreas que possuem um menor número de profissionais atuantes. De acordo com dados estatísticos do cadastro de profissionais do CREFITO 8, apenas $5 \%$ dos profissionais registrados trabalham na área de Saúde da Família, 0,3\%, em acupuntura e 3,7\%, na docência.

A concentração do número de profissionais jovens na faixa de renda que vai do piso salarial até 4 mil reais pode ser justificada pelos resultados que mostram dependência da renda em relação às variáveis faixa etária e tempo de formação. Quanto maior o tempo de formado e a faixa etária, maior a faixa de renda.

A Terapia Ocupacional é uma profissão relativamente jovem, se comparada a outras profissões da saúde, e sua história no Paraná teve início em 1980, com a criação do primeiro curso de graduação do estado. Sua expansão se deu nos últimos 10 anos, com a entrada no mercado de trabalho dos profissionais formados pelo segundo curso de graduação do estado. Desde então, um maior número de profissionais vêm sendo formado. No entanto, é compreensível que esses ainda não tenham atingido faixas de renda mais elevadas. Comparando-se com as fases da vida profissional do médico ${ }^{25}$, os terapeutas ocupacionais do Paraná encontram-se em início da vida profissional e firmando-se no mercado de trabalho.

As principais dificuldades apontadas estão relacionadas à remuneração, falta de identidade e reconhecimento profissional e falta de valorização da profissão, características das profissões que se encontram em processo de desenvolvimento.

\section{CONSIDERAÇÕES FINAIS}

O estudo permitiu traçar um perfil geral do terapeuta ocupacional do Paraná com base em uma amostra representativa.

$\mathrm{O}$ crescimento expressivo do número de profissionais no estado a partir de 2005, coincide com a formatura da primeira turma do curso público de Terapia Ocupacional na capital paranaense.

A expansão no número de profissionais que cursaram pós-graduação tanto lato quanto stricto sensu, 
demonstrou o aumento da preocupação da categoria com a educação permanente e a formação continuada e do poder público pelo aumento da oferta de residências multiprofissionais.

Observou-se que a maioria dos profissionais trabalha nas áreas tradicionais da profissão, que são Saúde Mental e Saúde Funcional. Contudo verificou-se um movimento de mudança desse padrão com o crescimento do número de profissionais trabalhando em Contextos Hospitalares e Contextos Sociais.

A atuação desse profissional na atenção primária ainda é incipiente, contrariando as possibilidades oferecidas pelas políticas públicas.

$\mathrm{O}$ estudo evidenciou que a maioria dos profissionais trabalha em instituições públicas municipais, o que demonstra a inserção dos terapeutas ocupacionais no SUS.

Os resultados relativos a renda mensal demonstraram que quanto maior o tempo de formado e a faixa etária, maior é a faixa de renda mensal. Diante disso, o fato de

\section{REFERÊNCIAS}

1. Faculdade de Medicina de Ribeirão Preto. Terapia Ocupacional. Ribeirão Preto: FMRP; 1997 [citado em 14 abr. 2016]. Disponível em: http://www.fmrp.usp.br/sitegraduacao/graduacao/cursos-oferecidos-pela-fmrp/terapiaocupacional/

2. Brasil. Decreto-Lei n. 938 de 13 de outubro de 1969. Provê sobre as profissões de fisioterapeuta e terapeuta ocupacional, e dá outras providências. Diário Oficial da União, Brasília; 1969 out. 13. Disponível em: https://www.planalto.gov.br/ ccivil_03/decreto-lei/1965-1988/Del0938.htm

3. Brasil. Ministério da Educação. Sistema e-MEC instituições de ensino superior e cursos de Terapia Ocupacional cadastrados no Brasil e no estado do Paraná [Internet]. Brasília: MEC; 2014 [citado 14 dez. 2014]. Disponível em: http://emec.mec.gov.br

4. Conselho Federal de Fisioterapia e Terapia Ocupacional. Número de terapeutas ocupacionais inscritos. 2014 [citado 14 dez. 2014]. Disponível em: www.coffito.org.br/site/.

5. Instituto Brasileiro de Geografia e Estatística. População brasileira total em 2014 [citado 14 dez. 2014]. Disponível em: http://www.ibge.gov.br/paisesat/main_frameset.php.

6. World Federation of Occupational Therapists. WFOT Human Resources Project 2014 [cited 2016 Jan 19]. Available from: http://www.wfot.org/resourcecentre.aspx. os terapeutas ocupacionais paranaenses não terem atingido faixas de renda elevada pode estar relacionado ao fato de a maioria dos profissionais serem jovens e a profissão ainda estar em fase de amadurecimento e consolidação.

O estudo requer aprofundamento no que diz respeito a tendências na formação e mercado de trabalho, mas já apresenta indicações que podem orientar a respeito de alguns aspectos como, por exemplo, na criação de cursos de pós graduação lato sensu específicos para terapeutas ocupacionais nas áreas em que há maior concentração de profissionais atuando, e no desenvolvimento de ações do controle social que poderão cobrar do poder público municipal o cumprimento das políticas públicas que recomendam a presença do terapeuta ocupacional nas ações da Atenção Primária em Saúde.

As possibilidades de exploração do perfil do profissional não foram esgotadas com este trabalho e novos estudos poderão ser desenvolvidos no sentido de explorar outras características do perfil.
7. Conselho Regional de Fisioterapia e Terapia Ocupacional da Oitava Região. Número de terapeutas ocupacionais inscritos no estado do Paraná [citado 17 nov. 2015]. Disponível em: http://www.crefito8.org.br/site/index.php?option=com content\&view $=$ article\&id $=163 \&$ Itemid $=19$.

8. Coury HJCG, Vilella I. Perfil do pesquisador fisioterapeuta brasileiro. Rev Bras Fisioter, São Carlos. 2009;13(4):356-63. doi: http://dx.doi.org/10.1590/S1413-35552009005000048.

9. Brasil. Lei n. 6.316, de 17 de dezembro de 1975. Cria o Conselho Federal e os Conselhos Regionais de Fisioterapia e Terapia Ocupacional e dá outras providências. Diário Oficial da União, Brasília; 1975 dez. 17; 154 da Independência e $87^{\circ}$ da República. Disponível em: http://www.planalto.gov. br/ccivil_03/Leis/1970-1979/L6316.htm.

10. Mângia EF. Uma década das Diretrizes Curriculares Nacionais: Terapia Ocupacional e as mudanças no ensino para o SUS [Editorial]. Rev Ter Ocup Univ Sao Paulo. 2012;23(1):i. doi: http://dx.doi.org/10.11606/issn.22386149.v23i1pi-i.

11. Akutsu RC. Os nutricionistas brasileiros: perfil profissional e demográfico. Rev Nutr, Campinas. 2008;21(1):7-19. doi: http://dx.doi.org/10.1590/S1415-52732008000100002.

12. Nozawa E, Sarmento GJV, Vega JM, Costa D, Silva JEP, Feltrim MIZ. Perfil de fisioterapeutas brasileiros que atuam 
em unidades de terapia intensiva. Fisioter Pesq, São Paulo. 2008;15(2):177-82. DOI: http://dx.doi.org/10.1590/S180929502008000200011.

13. Alves E, Rossi CE, Vasconcelos FAG. Nutricionistas egressos da Universidade Federal de Santa Catarina: áreas de atuação, distribuição geográfica, índices de pós-graduação e de filiação aos órgãos de classe. Rev Nutr, Campinas. 2003;16(3):295-304. doi: http://dx.doi.org/10.1590/S14155273200300030000 .

14. Krug JC. Formação e perfil do terapeuta ocupacional no Rio Grande do Sul em sintonia com o Sistema Único de Saúde [Dissertação]. Porto Alegre: Programa de Pós-graduação em Ensino na Saúde, Universidade Federal do Rio Grande do Sul; 2014. Disponível em: http://www.lume.ufrgs.br/bitstream/ handle/10183/108319/000948187.pdf? sequence $=1$.

15. Trelha CS, Gutierrez PR, Cunha ACV. Perfil demográfico dos fisioterapeutas da cidade de Londrina/PR. Salusvita, Bauru. 2003;22(2):247-56. Disponível em: http://www.usc. br/biblioteca/salusvita/salusvita_v22_n2_2003_art_05_por. pdf.

16. Pitta AMF. Hospital: dor e morte como ofício. 4a ed. São Paulo: Hucitec; 1999.

17. Castro AL, Faria MM, Adorno RCF, Zioni F. Mulher, mulher: saúde, trabalho, cotidiano. In: Alves PC, Minayo MCS. Saúde e doença: um olhar antropológico. Rio de Janeiro: Fiocruz; 1994. p.141-52.

18. Lancman S. Reflexão sobre uma trajetória na Terapia Ocupacional. Cad Ter Ocup UFSCar, São Carlos. 2012;20(3):471-8. doi: http://dx.doi.org/10.4322/ cto.2012.046.

19. Brasil. Lei n. 11.129 , de 30 de junho de 2005. Institui a Comissão Nacional de Residência Multiprofissional em Saúde no âmbito do Ministério da Educação. Diário Oficial da União, Brasília; 2005 jun. 30; 184 da Independência e $117^{\circ}$ da República. Disponível em: http://www.planalto.gov. br/ccivil_03/_Ato2004-2006/2005/Lei/L11129.htm.

20. Emmel MLG, Lancman S. Quem são nossos mestres e doutores? A avanço da capacitação docente em Terapia Ocupacional no Brasil. Cad Ter Ocup UFSCar, São Carlos. 1998;7(1):29-38. Disponível em: http://www. cadernosdeterapiaocupacional.ufscar.br/index.php/cadernos/ article/view/264/216.

21. Brasil. Lei n. 8.856, de $1^{\circ}$ de março de 1994. Fixa a Jornada de Trabalho dos Profissionais Fisioterapeuta e Terapeuta Ocupacional. Diário Oficial da União, Brasília; 1994 mar. 1; $173^{\circ}$ da Independência e $106^{\circ}$ da República. Disponível em: https://www.planalto.gov.br/ccivil_03/leis/18856.htm.

22. Mângia EF, Muramoto MT, Marques ALM. Formação profissional e serviços de saúde mental no SUS: estudo sobre a inserção de egressos do Curso de Terapia Ocupacional da FMUSP. Rev Ter Ocup Univ São Paulo. 2010;21(2):14857. doi: http://dx.doi.org/10.11606/issn.2238-6149. v21i2p148-157.

23. Brasil. Ministério da Saúde. Portaria n. 399, de 22 de fevereiro de 2006. Divulga o Pacto pela Saúde 2006: consolidação do SUS e aprova Diretrizes Operacionais do referido Pacto. Diário Oficial da União, Brasília; 2006 fev. 23, p.43.

24. Brasil. Ministério da Saúde. Portaria n. 3.088 de 23 de dezembro de 2011. Institui a rede de atenção psicossocial para pessoas com sofrimento ou transtorno mental e com necessidades decorrentes do uso de crack, álcool e outras drogas, no âmbito do Sistema Único de Saúde (SUS). Diário Oficial da União, n. 247, Brasília; 2011 dez. 26; Sec. 1:230/232 [citado 19 jan. 2016]. Disponível em: http://bvsms.saude.gov. br/bvs/saudelegis/gm/2011/prt3088_23_12_2011_rep.html

25. Machado MH. Os médicos no Brasil: um retrato da realidade. Rio de Janeiro: Fiocruz; 1997. 